\title{
Seed Reduction in Prairie Cordgrass, Spartina pectinata Link., by the Floret-Feeding Caterpillar Aethes spartinana (Barnes and McDunnough)
}

\author{
Jarrad R. Prasifka $\cdot$ D.K. Lee $\cdot$ Jeffrey D. Bradshaw • \\ Allen S. Parrish • Michael E. Gray
}

Published online: 9 March 2011

(C) The Author(s) 2011. This article is published with open access at Springerlink.com

\begin{abstract}
Insect damage to prairie cordgrass, Spartina pectinata Link., is conspicuously high in Illinois, where attempts to collect native seed show the majority of spikelets damaged with small holes. Dissection of spikes during summer reveals minute caterpillars boring though glumes and feeding on florets inside. In 2009-2010, panicles of prairie cordgrass from across its native range were used to estimate the percentage of insect-related damage and losses to seed production. Collections of caterpillars from panicles and stems were used to identify one floret-feeding species, estimate its distribution in the central USA, and assess its feeding patterns within spikes. Insect feeding damaged $38 \%$ of spikelets across eight states, though injury differed significantly between states. Regression of developed prairie cordgrass seeds onto insect damage suggests a 1:1 loss ratio (i.e., 50\% damaged spikelets reduces seed production by $50 \%$ ). Collections of caterpillars from six midwestern states suggest that larvae of a tortricid moth, Aethes spartinana (Barnes and McDunnough), are responsible for most insect damage to cordgrass spikelets. Larvae of $A$. spartinana generally feed
\end{abstract}

\section{J. R. Prasifka $(\triangle)$}

Energy Biosciences Institute, Institute for Genomic Biology,

University of Illinois,

Room 1117,

Urbana, IL 61801, USA

e-mail: prasifka@illinois.edu

D.K. Lee · A. S. Parrish • M. E. Gray

Department of Crop Sciences, University of Illinois,

Urbana, IL, USA

\section{J. D. Bradshaw}

Panhandle Research and Extension Center,

University of Nebraska-Lincoln,

Scottsbluff, NE, USA on a series of consecutive spikelets, with high infestations ( $>50 \%$ insect damage) showing damage concentrated in the middle of spikes. Because larvae are concealed by moving into adjacent spikelets and later tunneling into cordgrass stems, they may be difficult to control using insecticides. While direct effects of the caterpillar on biomass yields for prairie cordgrass are not known, for states like Illinois (where damage to spikelets often exceeds $70 \%$ ), breeding and seed production efforts may be severely limited without efforts to manage $A$. spartinana.

Keywords Biofuel $\cdot$ Biomass $\cdot$ Prairie $\cdot$ Pest $\cdot$ Yield

\section{Introduction}

Prairie cordgrass (Spartina pectinata Link.) is a perennial, warm-season $\left(\mathrm{C}_{4}\right)$ grass that reproduces both sexually through seeds and asexually by rhizomes. Native to North America, prairie cordgrass is predominantly found in low, poorly drained soils along roadsides, streams, meadows, marshes, and prairie potholes. Prairie cordgrass often forms dense, monospecific stands with biomass primarily consisting of leaves, but with stems that can grow 2 to $3 \mathrm{~m}$ tall [1-3]. Coastal members of the genus can be problematic as invasive weeds [4], but because of its tolerance to salinity and fluctuations in water levels, S. pectinata is considered important for stream bank stabilization and wetland habitat restoration [5-7]. More recently, prairie cordgrass has been considered as a dedicated bioenergy crop, in some cases producing dry mass yields comparable to more well-known perennials like switchgrass (Panicum virgatum L.) $[8,9]$.

As a bioenergy crop, prairie cordgrass has several advantages relative to some other candidate species. First, 
S. pectinata appears capable of producing significant biomass on lands considered unsuitable for many food and feed crops (because of flooding and salinity) with low agricultural inputs $[10,11]$. Second, while little artificial selection has taken place, it appears that there is significant genetic potential for improvement $[8,12]$. Third, $S$. pectinata can thrive at latitudes of the USA and Canada (up to $60^{\circ} \mathrm{N}$ ) where some other perennial, warm-season bioenergy crops cannot overwinter [3]. Also, unlike non-native plant species, prairie cordgrass may receive preferential treatment in terms of eligibility for subsidies or other public-sector incentives (e.g., evaluation by Council on Sustainable Biomass Production or Conservation Reserve Program standards). Finally, though prairie cordgrass can be planted using rhizomes or plugs (plantlets), the ability to establish plantings from seed provides flexibility relative to bioenergy crops such as Miscanthus $\times$ giganteus Greef and Deuter ex Hodkinson and Renvoize or Saccharum spp.

However, seed production can be challenging, leading to the generalization that "good seed [is] only sparingly produced" for Spartina spp. [13]. Partial self-incompatibility contributes to poor seed production in S. pectinata and its congeners, as smooth cordgrass (Spartina alterniflora Loisel) seed set approximately doubles between self- and cross-pollination [14]. Also, because S. pectinata exhibits protogynous flowering (stigmas exserted prior to anthers), chances for optimal seed set are restricted for both self- and cross-pollination. However, seed set in Spartina spp. is known to fluctuate [15] (from $92 \%$ to $18 \%$ in successive years for Spartina anglica C. E. Hubbard [16]), suggesting that under some conditions excellent seed production is possible.

Damage by insects also appears to be an important limitation to prairie cordgrass seed production in the central USA. Both native and planted stands may have panicles injured when grasshoppers are abundant, but the development of grasshopper populations and the damage they produce (partially consumed spikes, with individual spikelets often pointed in several directions) are conspicuous and may be effectively managed with insecticides. However, the destruction of developing florets by caterpillars may not be visible unless spikes are closely inspected to reveal the holes produced by larvae boring into the glumes. In Illinois, gently fanning out spikelets has shown more than three fourths of seed production lost to feeding by minute caterpillars (Fig. 1). Caterpillars removed from stems of prairie cordgrass in Illinois have been reared to adulthood and identified as Aethes spartinana (Barnes and McDunnough; Lepidoptera: Tortricidae), a species originally described from samples of prairie cordgrass collected in South Dakota [17]. Observations of A. spartinana [18] indicate adult moths lay small groups of eggs in the panicle, with larvae hatching and feeding on anthers and stigmas for about a week before tunneling into the stem. Larvae continue to feed, tunneling

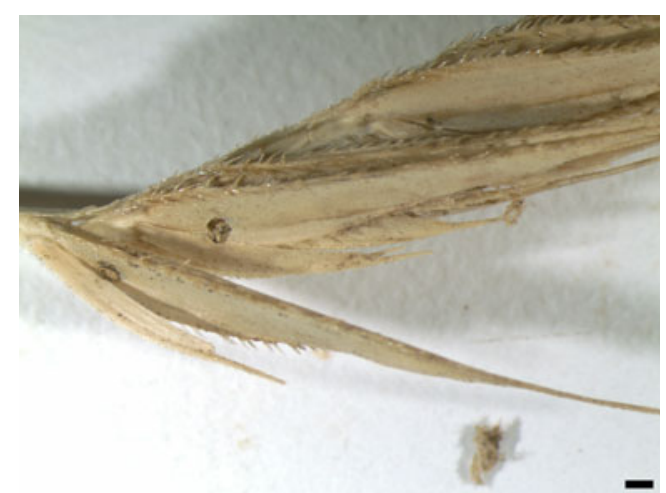

Fig. 1 Damage to prairie cordgrass spikelets by A. spartinana. Spike fanned out to reveal holes in glumes created as larvae bore through spikelets. Width of scale bar (bottom right) approximately $1 \mathrm{~mm}$

downward and overwintering in the base of the stem. In the spring, larvae exit the basal portion of stems from the previous year and enter newly emerged cordgrass tillers to continue larval development, pupate, and produce adult moths whose emergence coincides with flowering in prairie cordgrass.

Addressing the insect-related limitations to the production of S. pectinata seed is important for at least two reasons. First, the availability of large quantities of seed could make the process for growers to convert and scale-up plantings of prairie cordgrass relatively simple and inexpensive. Second, and perhaps more importantly, production of seed is necessary to efficiently select for prairie cordgrass varieties that are adapted for specific uses or regions; even without direct effects on biomass production, potential biomass gains from artificial selection may be significantly slowed by insect destruction of seed in plots used for breeding. To better understand the challenges insects present to seed production in established plantings of prairie cordgrass, mature panicles from native stands across the north-central and northeastern USA were collected and damage to individual spikelets assessed. Additionally, to refine the distribution of $A$. spartinana, prairie cordgrass in six midwestern states was surveyed during late summer for the presence of the caterpillars. Lastly, patterns of feeding by A. spartinana larvae were examined as a step toward mitigating the effect of the caterpillars on seed production.

\section{Methods}

Survey of Insect-Related Seed Losses

As part of efforts to collect germplasm representative of the natural range of prairie cordgrass in the USA, panicles were collected at 26 sites in Illinois, Connecticut, Wisconsin, 
Maine, Massachusetts, and Minnesota during October and November 2009. A single spike was removed from the lower-, middle-, and upper-third of each of three panicles, and spikelets were examined individually using a light box, which permitted them to be categorized as (a) damaged by insect feeding, (b) undamaged-containing seed, or (c) undamaged-without seed. Wide variation in the proportion of spikelets damaged by insects among sites (i.e., locations within each state) from the 2009 data suggested that sampling a greater number of panicles per site might provide more consistent estimates of insect damage, so greater numbers of panicles were collected from 13 sites in Illinois, Kansas, and Nebraska during November 2010. For these collections, 20 spikes were removed from among five to 15 panicles, with spikelets detached and mixed together. From each site, 100 spikelets were examined using a dissecting microscope, with each categorized as (a) damaged by insect feeding or (b) undamaged. For all spikelets categorized as damaged by insect feeding in 2009-2010, the appearance was as previously shown (Fig. 1); though generally minor, any damage by birds or grasshoppers was avoided. For states where fewer than three sites were sampled (Connecticut, Massachusetts), no statistical analysis beyond calculation of simple means was attempted. For the remaining states, a mixed-effects model was used to determine whether the percentage of insect-damaged spikelets in 2009-2010 varied among states (fixed effect) with site (within state) included as a random effect [19]. Because only Illinois was sampled in both years (and sites changed between years), data from Illinois in 2009 and 2010 were treated as distinct states in the analysis.

Details from the 2009 collection also allowed examination of the effect of insect feeding on $S$. pectinata seed production and an analysis of the sources of variation in insect damage estimates. Linear regression was used to test for a relationship between the percentage of spikelets with developed seeds and the percentage of insect-damaged spikelets [19]. Because sites within states had significant variation in the percentage of spikelets containing developed seeds, the regression was run excluding four sites where no damaged spikelets were found; this effectively eliminated sites where none of the variation in seed development could be assigned to insect feeding. Also, using a restricted maximum likelihood method, the relative contributions of state, site, stem, and spike position (random effects) as variance components in insect damage data were calculated [19] to help determine how future sampling effort should be allocated.

\section{Distribution of $A$. spartinana}

Early scientific literature on $A$. spartinana establishes this species as present in South Dakota and Iowa $[17,18]$, with claims of distribution covering "the Canadian boundary to Southern Iowa" [18]. A more recent account notes $A$. spartinana collected in Canada from Manitoba and Nova Scotia with additional records in the USA from Wyoming and Massachusetts [20]. Anecdotal evidence suggests that the species may be present south of the known distribution, including several additional states in the midwestern USA. During August and September of 2009, collections of prairie cordgrass stems and panicles were made in Indiana, Illinois, Missouri, Kansas, Nebraska, and Iowa. Except for Missouri and Kansas, where single-species plantings were sampled at National Resource Conservation Service (NRCS) Plant Materials Centers, all collections were made from uncultivated (roadside) stands of prairie cordgrass.

After collection, plants were dissected to remove any caterpillars found in the panicle or stems, with larvae from each plant part preserved in $70 \%$ ethanol for future examination. Additional larvae from a prairie restoration site in Savoy, Illinois were collected in the spring and placed live onto potted prairie cordgrass plants to rear adult moths, establishing the relationship between adult moths and the larvae, which have only been described very generally [18]. Specimens from each location where larvae were collected, along with adults from the Savoy, Illinois site, were submitted to the United States Department of Agriculture's (USDA) Systematic Entomology Lab for examination and preservation as vouchers. Additional information regarding the timing of larval activity or movement (i.e., from panicle to stem in late summer, from old stem to new growth in spring) was also noted in the course of collecting specimens.

\section{Patterns of A. spartinana Larval Feeding}

Among lepidopteran pests, species whose larvae feed internally can be difficult to control [21], as their feeding may shelter them from exposure to insecticides. Patterns of A. spartinana feeding were examined on spikes of prairie cordgrass to assess the degree to which feeding behavior may protect larvae from exposure to insecticides. During August 2009, panicles $(n=10)$ were removed from cordgrass plants at a prairie restoration site in Savoy, Illinois. A single spike was removed from the lower-, middle-, and upper-third of each panicle, and spikelets were examined individually, in order from the most basal spikelet using a dissecting microscope. For each spikelet, the number of holes indicative of $A$. spartinana feeding was noted, as was the presence of larvae. To determine if the distribution of larvae or damage from their feeding was related to position on spikes, chi-squared tests examined whether larvae or damaged spikelets were evenly distributed among quartiles on cordgrass spikes; separate analyses were conducted for spikes with low $(<50 \%)$ and high $(>50 \%)$ levels of damaged spikelets. 


\section{Results}

From all sampled locations in 2009-2010, 10,091 spikelets were examined with insect damage apparent on 3,867 $(38 \%)$. The percentage of spikelets with insect damage varied significantly among states $\left(F_{6,27}=6.09, P<0.001\right)$; in general, insect damage appeared greatest in Illinois and Wisconsin and lowest in Minnesota, while damage to seeds in Maine, Kansas, and Nebraska was intermediate and similar to the other states sampled (Fig. 2). The percentage of insect-damaged spikelets in Illinois did not differ between 2009 and 2010. Estimates of insect damage at individual sites and site location data are shown in Table 1.

Though only an average of $12 \%$ of spikelets contained seeds in 2009, regression of the percentage of developed seeds onto insect damage indicates that insects can be a limiting factor for prairie cordgrass seed production. Across 19 sites in four states, analysis suggests nearly half of the variability in seed development could be explained by insect damage (Fig. 3). Analysis of the variance components in 2009 data indicates estimates of insect damage in the USA could be significantly improved by including additional states and sites, as differences at these levels were the largest sources of variability. The estimated variance components for state (726) and site (356) were followed by experimental error (269) and stem (238), with almost no variability explained by spike position $(<1)$.

The identity of adult moths reared from stems of prairie cordgrass was confirmed as $A$. spartinana based on the appearance of male genitalia. Larvae collected from panicles and stems at all six midwestern states are believed to be $A$. spartinana based on the known biology of this insect $[17,18]$, the successful rearing of adults from larvae collected in prairie cordgrass in Illinois, and the clear

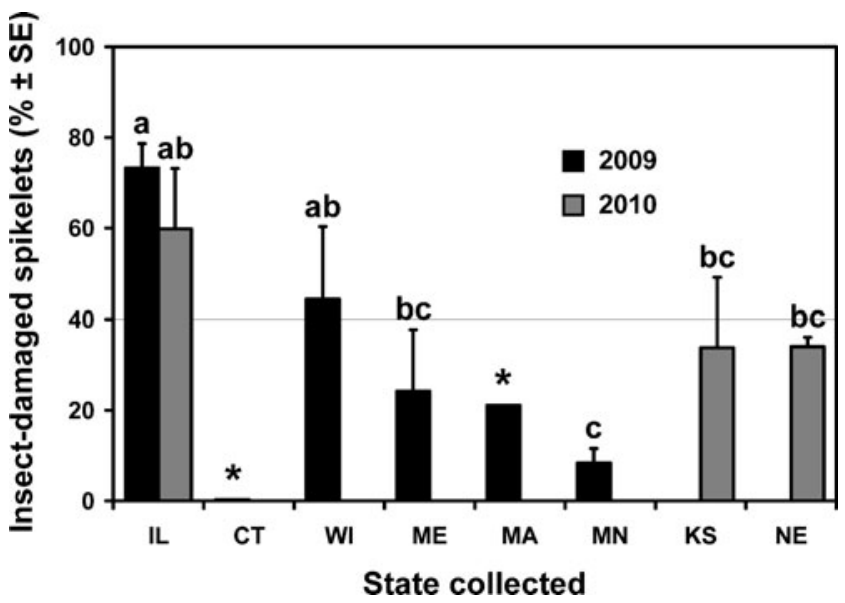

Fig. 2 Insect damage (mean $\pm \mathrm{SE}$ ) to prairie cordgrass spikelets, 2009-2010. Significant differences between states shown by different lowercase letters. Locations with insufficient data for means comparisons (less than three sites) indicated by asterisks
Table 1 Estimates of damage by floret-feeding insects in prairie cordgrass, 2009-2010

\begin{tabular}{|c|c|c|c|c|c|}
\hline Year & State & Site $^{a}$ & Latitude & Longitude & $\begin{array}{l}\text { Damage } \\
(\%)^{\mathrm{b}}\end{array}$ \\
\hline \multirow[t]{26}{*}{2009} & \multirow[t]{6}{*}{ Illinois } & Homer & 40.0047 & -88.0100 & 50 \\
\hline & & Sidney & 40.0111 & -88.0203 & 76 \\
\hline & & Champaign & 40.0550 & -88.3072 & 92 \\
\hline & & Urbana & 40.1133 & -88.1486 & 73 \\
\hline & & Dixon & 41.8308 & -89.4344 & 76 \\
\hline & & Savanna & 42.1783 & -90.2036 & 73 \\
\hline & \multirow[t]{2}{*}{ Connecticut } & Stonington & 41.3500 & -71.9092 & 0 \\
\hline & & Bethany & 41.4667 & -73.0017 & 1 \\
\hline & \multirow[t]{5}{*}{ Wisconsin } & Readstown & 43.4461 & -90.7800 & 87 \\
\hline & & Portage & 43.5242 & -89.4975 & 62 \\
\hline & & Necedah & 44.0536 & -90.0897 & 56 \\
\hline & & Augusta & 44.6614 & -91.0542 & 15 \\
\hline & & Cumberland & 45.5061 & -92.0200 & 0 \\
\hline & \multirow[t]{4}{*}{ Maine } & Lincolnville & 44.2681 & -69.0169 & 36 \\
\hline & & Gouldsboro & 44.4906 & -68.0172 & 0 \\
\hline & & Steuben & 44.5278 & -67.8872 & 57 \\
\hline & & Bath & 43.9206 & -69.8639 & 4 \\
\hline & Massachusetts & Danvers & 42.5603 & -70.9219 & 21 \\
\hline & \multirow[t]{8}{*}{ Minnesota } & Winthrop & 44.5436 & -94.2950 & 13 \\
\hline & & Hector & 44.7533 & -94.7931 & 0 \\
\hline & & Milan & 45.1517 & -95.9614 & 4 \\
\hline & & Fergus Falls & 46.1808 & -96.0194 & 26 \\
\hline & & Barnesville & 46.6742 & -96.4253 & 15 \\
\hline & & Fosston & 47.5906 & -95.7881 & 0 \\
\hline & & Crookston & 47.8114 & -96.6108 & 3 \\
\hline & & Stephen & 48.5144 & -96.8869 & 5 \\
\hline \multirow[t]{13}{*}{2010} & \multirow[t]{4}{*}{ Kansas } & Abilene & 38.9092 & -97.2456 & 32 \\
\hline & & Manhattan & 39.1010 & -96.6083 & 20 \\
\hline & & Manhattan & 39.1364 & -96.6353 & 6 \\
\hline & & $\begin{array}{l}\text { Manhattan- } \\
\text { NRCS }\end{array}$ & 39.1383 & -96.6331 & 77 \\
\hline & \multirow[t]{6}{*}{ Illinois } & Sidney & 40.0264 & -88.0192 & 71 \\
\hline & & Savoy & 40.0744 & -88.2481 & 92 \\
\hline & & St. Joseph & 40.1131 & -88.0247 & 25 \\
\hline & & Rossville & 40.4072 & -87.5614 & 25 \\
\hline & & Hoopeston & 40.4592 & -87.7633 & 89 \\
\hline & & Monmouth & 40.8339 & -90.6511 & 57 \\
\hline & \multirow[t]{3}{*}{ Nebraska } & Cozad & 40.8853 & -100.0614 & 38 \\
\hline & & Brady & 41.0472 & -100.4219 & 33 \\
\hline & & Maxwell & 41.0839 & -100.5378 & 31 \\
\hline
\end{tabular}

\footnotetext{
${ }^{a}$ Identified by nearest town. Sites consisted of mixed species areas (e.g., roadsides, prairie) except one single-species planting used for biomass research at Manhattan-NRCS

${ }^{\mathrm{b}}$ Assessment of damage based on inspection of spikelets for holes using light box or dissecting microscope
}

similarity of larvae from sampling in the other five states. Further, larval specimens from prairie cordgrass panicles 


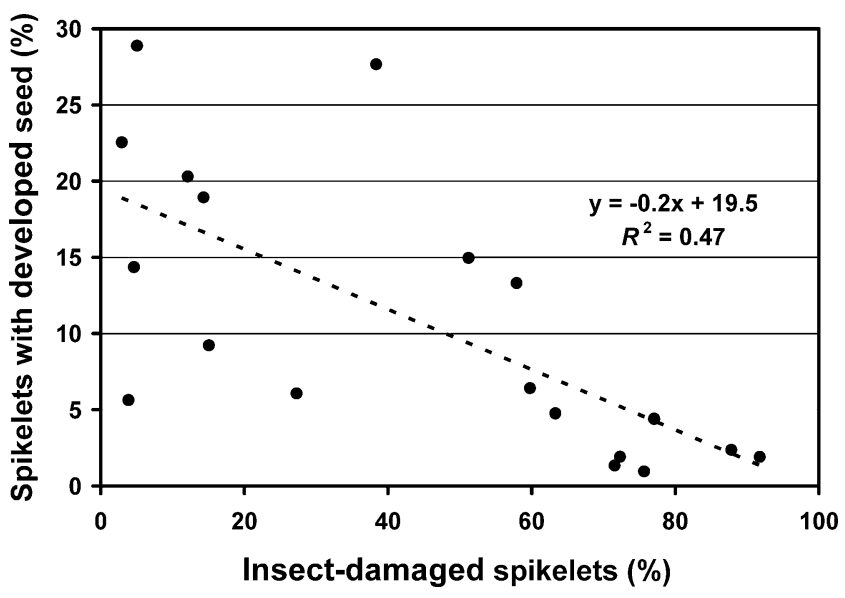

Fig. 3 Regression of prairie cordgrass seed production on insect damage, 2009. Scatter plots, regression equation, and coefficient of determination for 19 sites across four states

and stems were from the tribe Cochylini; the only other tortricid caterpillar (perhaps erroneously) reported to use prairie cordgrass as a host, Clepsis (Tortrix) clemensiana (Fern.) [17], is in the tribe Archipinae and has a larval appearance clearly distinct from $A$. spartinana [22]. The presence of $A$. spartinana is most easily detected by examining spikes after cordgrass anthesis. In central Illinois, larvae appeared most common in panicles during August but were found from late July to mid-September. However, larger larvae were found in stems starting in late April, when their tunneling stunted infested prairie cordgrass; feeding by overwintered larvae on newly emerged cordgrass in the spring produces symptoms of infestation similar to those produced by early-season stem borers in switchgrass [23]. The life stages of A. spartinana on prairie cordgrass are shown in Fig. 4.

Feeding damage on panicles collected in late August in Savoy, Illinois ranged from about $20 \%$ to $75 \%$ (mean $\% \pm$

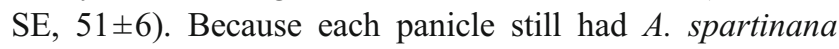
larvae within spikelets (not yet moved into stems), damage at this site is probably underestimated. Subsequent collections at this site detected larvae in panicles for at least two more weeks (to mid-September). Even when a high percentage of spikelets were damaged, anthers and stigmas often remained attached, suggesting that the larvae may
Fig. 4 Life stages of $A$. spartinana. Photographs include a larva in spikelet, b larva inside stems (winter), c larva and pupa inside stems, and $\mathbf{d}$ adult. All plant parts are of prairie cordgrass. Width of scale bars (bottom right for each photo) approximately $1 \mathrm{~mm}$

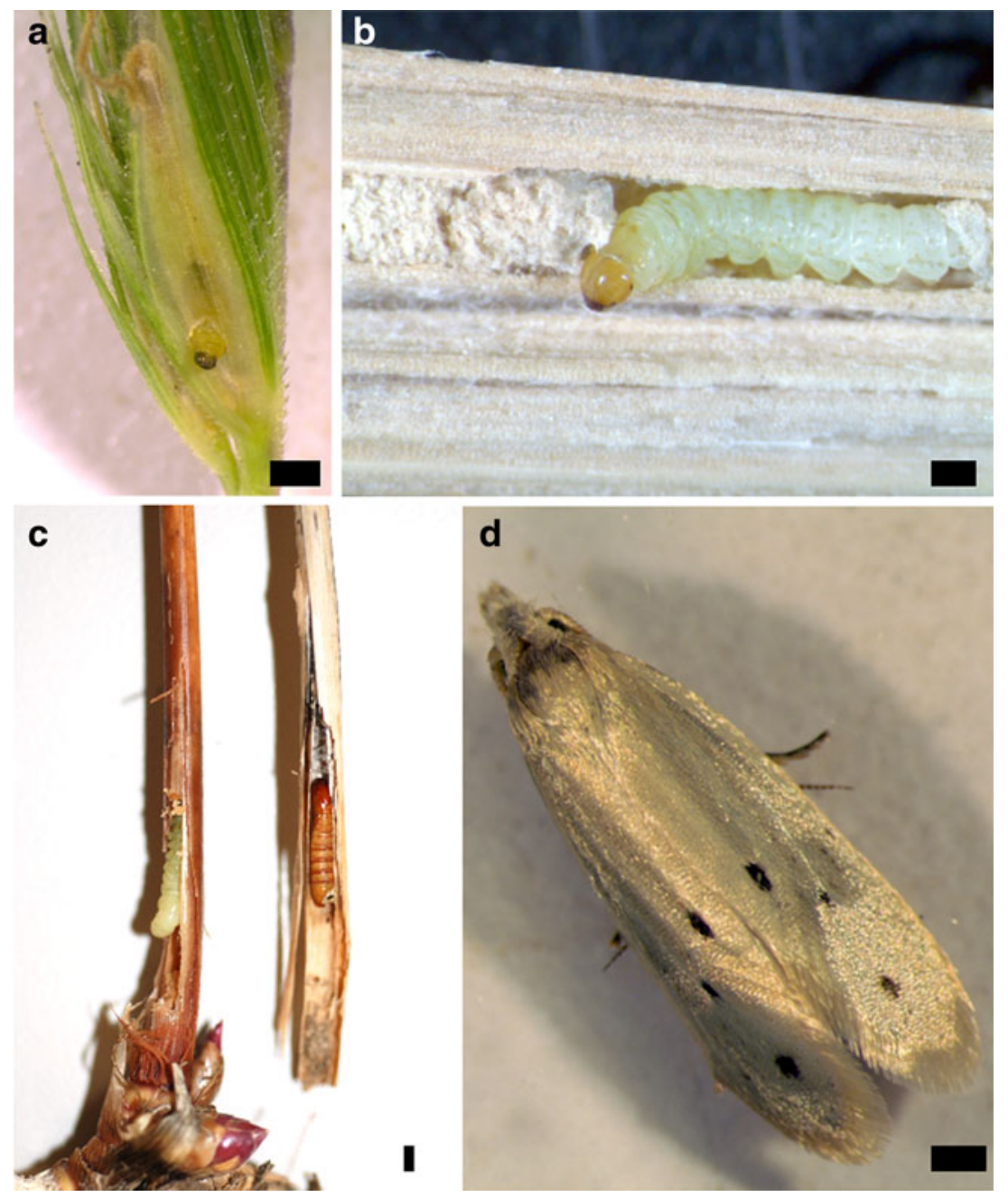


feed more on the ovary than previously reported [18]. Examples of feeding patterns from spikes with low, moderate, and high levels of caterpillar feeding (Fig. 5) suggest that a single larva will typically make two holes per spikelet, presumably to enter and exit, and feed on a series of adjacent spikelets. Small larvae are often contained within a spikelet, but caterpillars may also physically span several consecutive spikelets as they feed concealed in a spike. Also, for spikes with high levels of infestation, the numbers of holes per spikelet (often four or more) suggest larvae often move into spikelets that have previously been occupied. Based on the location of $A$. spartinana larvae on infested plants, caterpillars did not appear to have a preference for any section on a spike (by quartile; $\chi^{2}$ test, $d f=3, P>0.05$ ). However, for spikes with $<50 \%$ damage, feeding was greater on the lower (proximal) quartiles $\chi^{2}=34.60, P<0.001$; on spikes with $>50 \%$ damage, the middle quartiles received more damage relative to upper and lower quartiles $\left(\chi^{2}=47.00, P<0.001\right.$; Fig. 6$)$.

\section{Discussion}

Though nearly $40 \%$ of prairie cordgrass spikelets were damaged by floret-feeding insects across eight states (Fig. 2), potential for even greater losses exists if plantings of prairie cordgrass expand, as indicated by sites in Illinois, Wisconsin, and Kansas with $>75 \%$ of spikelets damaged. The percentage of developed prairie cordgrass seeds regressed onto insect damage suggests that for native stands, the ratio of seed damage to loss is nearly 1 (e.g.,

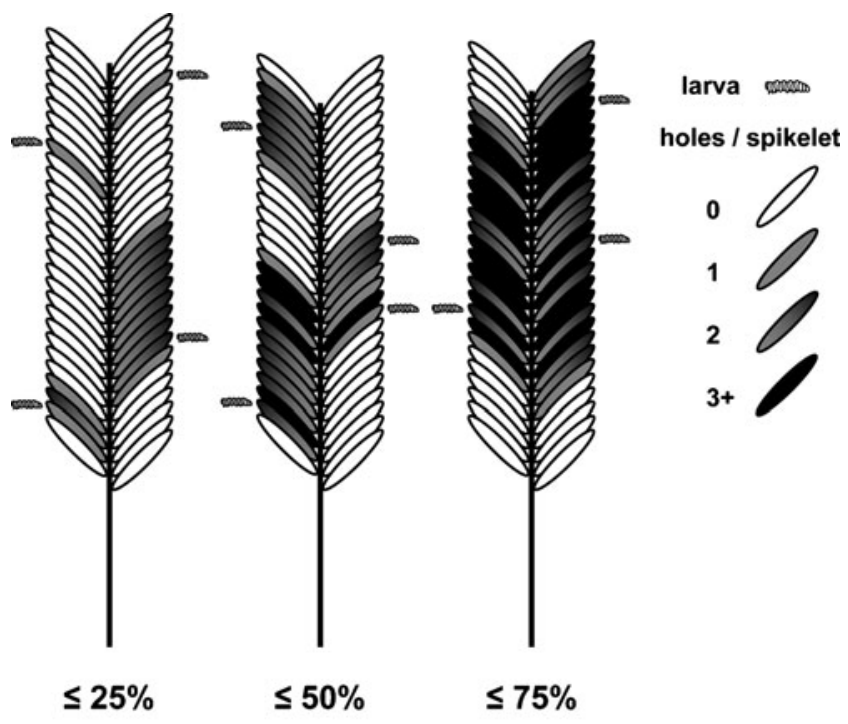

\section{Percentage of spikelets damaged}

Fig. 5 Patterns of spikelet feeding by A. spartinana. Diagram showing location of larvae and holes from boring into and out of spikelets with $\leq 25 \%, 50 \%$, and $75 \%$ damage

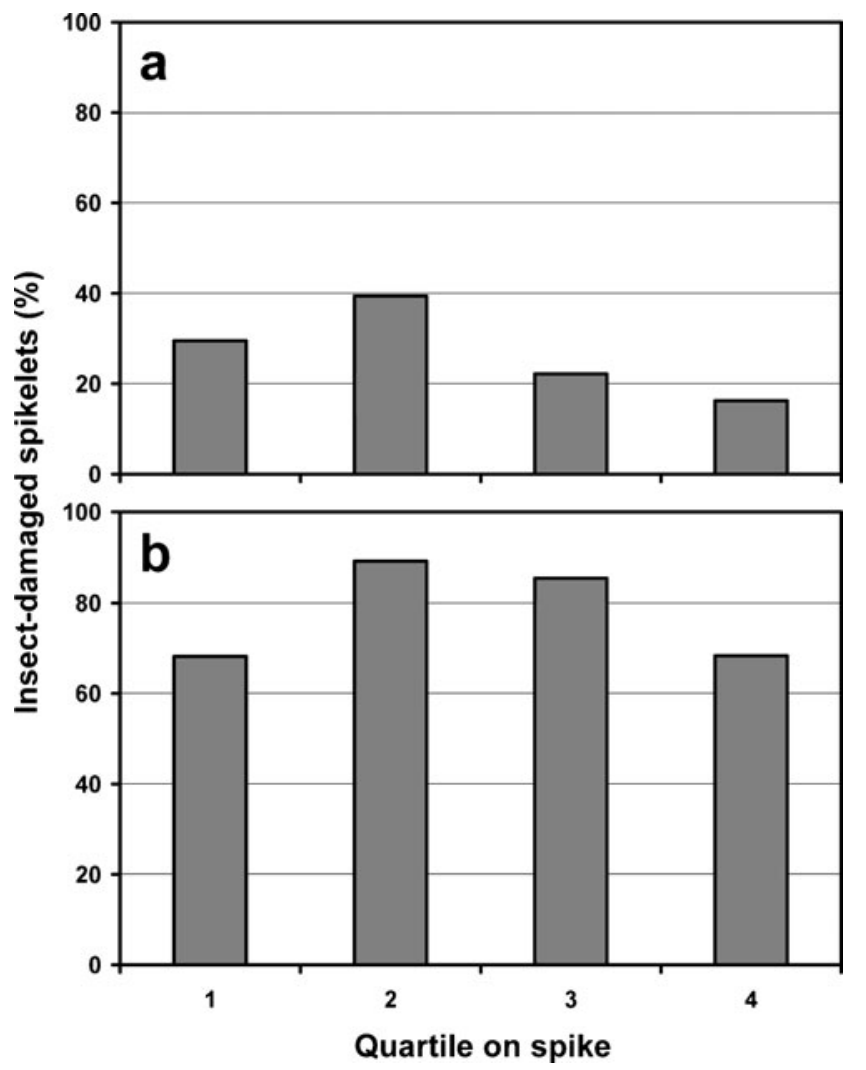

Fig. 6 A. spartinana spikelet damage by quartile. Percentage of insect-damaged spikelets by quartile $(1=$ basal $)$. From 30 spikes, samples divided into those with $\mathbf{a}<50 \%$ and $\mathbf{b}>50 \%$ damaged spikelets. Range of spikelet numbers per quartile, a 226-230 and b 215-221

seed production decreased from $20 \%$ to $10 \%$ as insect damage approached $50 \%$; Fig. 3). This response to floret damage is similar to that seen in sunflower [24], whose florets and developing seeds are consumed by larvae of the banded sunflower moth, Cochylis hospes Walsingham. Combined, data on spikelet damage and seed development suggest that breeding and seed production may be severely limited for several states; indeed, consistently high levels of insect damage in Missouri prevented seed distribution of a prairie cordgrass ecotype developed for habitat restoration (Jerry Kaiser, USDA-NRCS, Elsberry, MO, personal communication). Based on variance components in 2009 data, future regional estimates of insect damage would benefit most from sampling greater numbers of states and sites; however, for sampling intended to focus on a single state, additional stems per site would also improve estimates of damage.

Collection of larvae from prairie cordgrass in six midwestern states expands the known geographic range of A. spartinana, with insect feeding data from Minnesota and Wisconsin also suggesting that the species is present. Based on records of adults collected as far east as Massachusetts [20], A. spartinana appears to be the cause of most, if not 
all, of the holes bored into spikelets in the central and northeastern USA. However, it also is possible a closely related species (for which larval hosts are mostly unknown [25]) is responsible for floret damage in prairie cordgrass along the east coast. A. spartinana has been described as a floret-feeding insect [18], but because caterpillars can be collected in panicles in central Illinois as late as midSeptember (almost 2 months after flowering begins), it seems possible larvae also may feed on developing ovules well after pollination.

Patterns of damage along infested spikes (Fig. 5) suggest that like other insects that feed inside host plants, control of A. spartinana with insecticides may be difficult. It appears that typical larval feeding behavior is to enter a spikelet and remain concealed by feeding on several consecutive spikelets until moving into the stem. Unless insecticides with systemic or translaminar properties can effectively control larvae feeding on florets, only two brief periods are available to control A. spartinana larvae with insecticides; the later period, when larvae leave spikes and move into cordgrass stems, is after considerable damage to seed production has already occurred. Further, observations in Savoy, Illinois show larvae present for a period of at least 6 weeks; combined with observations of adult emergence lasting a month or more [18], it seems unlikely that a single insecticide application can adequately protect seed production. The effect of relatively greater damage to the middle of spikes (with $>50 \%$ damage) by $A$. spartinana may not be immediately apparent. However, in Sweden, larvae of the congener Aethes deutschiana Zetterstedt feed more heavily toward the middle of inflorescences of their host (Bartsia alpina L., a perennial herb); because these nodes produce relatively more seed from self-pollination, feeding by $A$. deutschiana effectively increases the proportion of seeds produced by outcrossing [26].

Though high levels of insect damage (particularly Illinois and Wisconsin) and observations on the biology of $A$. spartinana suggest management of this pest may be difficult, a better understanding of this insect and related pest species may provide the insight needed to develop alternatives to repeated applications of broad-spectrum insecticides. For example, in central Illinois, where many native stands of prairie cordgrass have $\approx 75 \%$ of florets damaged, other nearby $(<5 \mathrm{~km})$ sites appear to have little or no A. spartinana. Anecdotally, sites with very low levels of damaged spikelets appear to be those which do not consistently produce significant numbers of reproductive tillers (e.g., on roadsides that may be periodically mowed). One explanation for this pattern is that newly hatched larvae cannot survive without access to developing florets. This suggests unconventional insect management strategies for plots intended for seed production; if early-season cutting (or other measures) could significantly alter flower- ing time for prairie cordgrass, the relative absence of florets could reduce $A$. spartinana populations enough to allow seed production. Other management practices also could limit the abundance of $A$. spartinana. For example, though some larvae appear to overwinter below ground, stems cut above ground level in the fall can contain multiple caterpillars, suggesting that harvest of dried biomass at the earliest practical time could greatly reduce overwintering populations. Also, observations at one site in central Illinois suggest that burning residue in the spring may produce significant mortality of overwintered larvae. Because of their low cost and simplicity, such cultural practices should be directly tested for their value in limiting $A$. spartinana populations in prairie cordgrass. However, if the use of insecticides proves necessary, the environmental impacts of insect management could be reduced by using existing information on similar, closely related pests to inform efforts to manage $A$. spartinana. Research on floret-feeding species like $C$. hospes should enable a combination of tools such as microbial insecticides [27], insect-growth regulators, and host plant resistance [28], to reduce the effects of A. spartinana on prairie cordgrass seed production while limiting the use of broad-spectrum insecticides.

Acknowledgments Research funding was provided by the Energy Biosciences Institute. The authors wish to thank several additional contributors to the project. Rich Wynia (USDA-NRCS, Manhattan, KS), Jerry Kaiser, and Steve Bruckerhoff (USDA-NRCS, Elsberry, $\mathrm{MO}$ ) assisted in locating stands of prairie cordgrass and provided information on previous problems with A. spartinana. Bret Hash (Schaumburg, IL) helped with larval collections and the dissection of infested prairie cordgrass spikes. Eric Metzler (Alamogordo, NM) provided initial confirmation of adult moths reared from prairie cordgrass. John Brown (USDA-SEL, Washington, DC) confirmed the identity of adult moths and caterpillars from prairie cordgrass panicles and stems.

Open Access This article is distributed under the terms of the Creative Commons Attribution Noncommercial License which permits any noncommercial use, distribution, and reproduction in any medium, provided the original author(s) and source are credited.

\section{References}

1. Hitchcock AS (1950) Manual of the grasses of the United States. U.S. Government Printing Office, Washington

2. Mobberley DG (1956) Taxonomy and distribution of the genus Spartina. Iowa State Coll J Sci 30:471-574

3. Barkworth ME, Anderton KM, Capels KM, Long S, Piep MB (2007) Manual of the grasses for North America. Utah State University Press, Logan

4. Grevstad FS (2005) Simulating control strategies for a spatially structured weed invasion: Spartina alterniflora (Loisel) in Pacific Coast estuaries. Biol Invasions 7:665-677

5. Fraser A, Kindscher K (2005) Spatial distribution of Spartina pectinata transplants to restore wet prairie. Restor Ecol 13:144 151 
6. Bonilla-Warford CM, Zedler JB (2002) Potential for using native plant species in stormwater wetlands. Environ Manag 29:385-394

7. Montemayor MB, Price JS, Rochefort L, Boudreau S (2008) Temporal variations and spatial patterns in saline and waterlogged peat fields: 1. Survival and growth of salt marsh graminoids. Environ Exp Bot 62:333-342

8. Boe A, Lee DK (2007) Genetic variation for biomass production in prairie cordgrass and switchgrass. Crop Sci 47:929-934

9. Madakadze IC, Coulman BE, Mcelroy AR, Stewart KA, Smith DL (1998) Evaluation of selected warm-season grasses for biomass production in areas with a short growing season. Bioresour Technol 65:1-12

10. Boe A, Owens V, Gonzalez-Hernandez J, Stein J, Lee DK, Koo BC (2009) Morphology and biomass production of prairie cordgrass on marginal lands. GCB Bioenergy 1:240-250

11. Potter L, Bingham MJ, Baker MG, Long SP (1995) The potential of two perennial $\mathrm{C}_{4}$ grasses and a perennial $\mathrm{C}_{4}$ sedge as lignocellulosic fuel crops in NW Europe: crop establishment and yields in E. England. Ann Bot 76:513-520

12. Moncada KM, Ehlke NJ, Muehlbauer GJ, Sheaffer CC, Wyse DL, DeHaan LR (2007) Genetic variation in three native plant species across the state of Minnesota. Crop Sci 47:2379-2389

13. Gleason HA, Cronquist A (1991) Manual of vascular plants of Northeastern United States and adjacent Canada. The New York Botanical Garden, Bronx

14. Fang X, Subudhi PK, Venuto BC, Harrison SA (2004) Mode of pollination, pollen germination, and seed set in smooth cordgrass (Spartina alterniflora, Poaceae). Int J Plant Sci 165:395-401

15. Gray AJ, Marshall DF, Raybould AF (1991) A century of evolution in Spartina anglica. Adv Ecol Res 21:1-62
16. Goodman PJ, Braybrooks EM, Marchant CJ, Lambert JM (1969) Spartina $\mathrm{x}$ townsendii H. \& J. Groves sensu lato. J Ecol 57:298-313

17. Barnes W, McDunnough J (1916) An apparently new species of Phalonia. Can Entomol 48:144

18. Ainslie CN (1917) A few notes on the life history of Phalonia spartinana. Can Entomol 49:93-96

19. SAS Institute Inc (2007) SAS 9.1.3 help and documentation. SAS Institute, Cary

20. Razowski J (1997) Cochylini (Lepidoptera: Tortricidae) of Canada. Acta Zool Cracov 40:107-163

21. Nault BA, Kennedy GG (1996) Timing insecticide applications for managing European corn borer (Lepidoptera: Pyralidae) infestations in potato. Crop Prot 15:465-471

22. MacKay MR (1962) Larvae of the North American Tortricinae (Lepidoptera: Tortricidae). Can Entomol Suppl 28:1-182

23. Prasifka JR, Bradshaw JD, Boe AA, Lee DK, Adamski D, Gray ME (2009) Symptoms, distribution and abundance of the stemboring caterpillar, Blastobasis repartella (Dietz), in switchgrass. Bioenergy Res 3:238-242

24. Charlet LD, Miller JF (1993) Seed production after floret removal from sunflower heads. Agron J 85:56-58

25. Sabourin M, Miller WE, Metzler EH, Vargo JT (2002) Revised identities and new species of Aethes from midwestern North America (Tortricidae). J Lepid Soc 56:216-233

26. Molau U, Eriksen B, Knudsen JT (1989) Predispersal seed predation in Bartsia alpina. Oecologia 81:181-185

27. Jyoti JL, Brewer GJ (1999) Median lethal concentration and efficacy of Bacillus thuringiensis against banded sunflower moth (Lepidoptera: Tortricidae). J Econ Entomol 92:1289-1291

28. Charlet LD, Brewer GJ (1995) Resistance of native sunflowers (Asterales: Asteraceae) to the banded sunflower moth (Lepidoptera: Cochylidae). Environ Entomol 24:1224-1228 